\title{
Estimating biophysical properties of coffee (Coffea canephora) plants with above-canopy field measurements, using CropSpec ${ }^{\circledR} * * *$
}

\author{
Bayu T. Widjaja Putra ${ }^{1,2}$, Peeyush Soni ${ }^{1}{ }^{*}$, Eiji Morimoto ${ }^{3}$, and Pujiyanto Pujiyanto ${ }^{4}$ \\ ${ }^{1}$ Agricultural Systems and Engineering, School of Environment, Resources and Development (SERD), Asian Institute of Technology, \\ Pathum Thani 12120, Thailand \\ ${ }^{2}$ Faculty of Agricultural Technology, Jember University, Jember 68121, East Java, Indonesia \\ ${ }^{3}$ Laboratory of Bioproduction System Engineering, Faculty of Agriculture, Tottori University, 4-101 Koyama Tottori, \\ 680-8553, Japan \\ ${ }^{4}$ Indonesian Coffee and Cocoa Research Institute (ICCRI), Jember, East Java, Indonesia
}

Received April 3, 2017; accepted January 11, 2018

\begin{abstract}
Remote sensing technologies have been applied to many crops, but tree crops like Robusta coffee (Coffea canephora) under shade conditions require additional attention while making above-canopy measurements. The objective of this study was to determine how well chlorophyll and nitrogen status of Robusta coffee plants can be estimated with the laser-based (CropSpec $\circledR$ ) active sensor. This study also identified appropriate vegetation indices for estimating Nitrogen content by above-canopy measurement, using near-infra red and red-edge bands. Varying light intensity and different background of the plants were considered in developing the indices. Field experiments were conducted involving different non-destructive tools (CropSpec ${ }^{\circledR}$ and SPAD-502 chlorophyll meter). Subsequently, Kjeldahl laboratory analyses were performed to determine the actual Nitrogen content of the plants with different ages and field conditions used in the non-destructive previous stage. Measurements were undertaken for assessing the biophysical properties of tree plant. The usefulness of near-infrared and red-edge bands from these sensors in measuring critical nitrogen levels of coffee plants by above-canopy measurement are investigated in this study.

Keywords: CropSpec ${ }^{\circledR}$, Coffea canephora, above-canopy measurement, nitrogen content, chlorophyll content
\end{abstract}

\section{INTRODUCTION}

Coffee is estimated to be the main income source of few million families who mostly inhabit remote rural areas. In practice, cultivation of Robusta coffee is done using

*Corresponding author e-mail: soni.ait@gmail.com

**The research was supported by the General Directorate of Higher Education (DIKTI-Indonesia), and the Asian Institute of Technology (Thailand). The authors would also like to acknowledge the support received from TOPCON JAPAN in providing the CropSpec $\AA$ active nitrogen sensor, and the Indonesian Coffee and Cocoa Research Institute (ICCRI) for facilitating in-field data collection (2015-2016). conventional or traditional techniques, where application of fertilizer is usually not in accordance with the sustainable agriculture principles (ICCRI, 1999). The advanced technologies using non-destructive methods for on-farm management of tropical plants may increase effective use of labor, reduce the human error, and improve the competitiveness (Athmaselvi et al., 2014; Makky et al., 2014).

Nutrient management is also highly considered in addressing uncertain climate and sustainably increasing the yield (Ortiz et al., 2008). Nitrogen (N) management is a key challenge associated with ensuring sustainability of coffee production. Both excess and deficient fertilization of $\mathrm{N}$ are common problems in coffee production. Excessive $\mathrm{N}$ fertilization reduces economic return, decreases quality and quantity of the yields and increases pollution. Whereas, deficiency of $\mathrm{N}$ results in increased vulnerability to pest and disease, lower quality and quantity of yields, and reduced smallholder economic return (Bongiovanni and Lowenberg-Deboer, 2004; Campbell et al., 1995). In addition, smallholders with limited scientific knowledge or lack of measuring tools tend to excessively apply $\mathrm{N}$ (Sitthaphanit et al., 2009).

Determining critical levels of $\mathrm{N}$ in plants is crucial for effective, as well as efficient $\mathrm{N}$ management. This can be usually done by two different approaches. The first is destructive analysis, where chemical laboratory test of leaf tissue is used to identify $\mathrm{N}$ content. For a large plantation area or for a truly representative $\mathrm{N}$ content measurement

(C) 2018 Institute of Agrophysics, Polish Academy of Sciences 
for each plant, this method is not suitable as it is expensive and time consuming. Moreover, only a few plants can be randomly sampled for an entire field, and these may not adequately represent the in-field variability of $\mathrm{N}$ content of each plant (Fitzgerald et al., 2010).

The second approach employs remote sensing technologies. These technologies could help in identifying the optimum application of nitrogen corresponding to different growth stages and field conditions. Most techniques report indirect nitrogen content through estimating leaf chlorophyll content; as the chlorophyll and nitrogen content in leaves are highly correlated. However, leaves also contain many pigments other than the chlorophyll pigments, which may affect the estimation, especially for tree crops (Riccardi et al., 2014) when using above-canopy and direct-leaf measurements. In addition, chlorophyll content in plant leaves is also affected by intensity of the incoming light to the leaves, water content in the soil, pests and diseases and also lack of other nutrients such as sulphur (S).

Recently, there has been an increased interest in applications of direct-leaf and above-canopy sensors, and especially the commercially available active sensors, in estimating critical levels of $\mathrm{N}$ in plants. Commonly used leaf canopy active sensors include CropSpec ${ }^{\circledR}$, Green Seekers ${ }^{\circledR}$ and CropCircle ${ }^{\circledR}$. Direct-leaf sensors like SPAD502 chlorophyll meter are also widely used in estimating $\mathrm{N}$ content. However, most of these tools are employed in open fields where incident light is mostly uniform, like in cereal crops such as paddy, wheat and corn.

Only a few research studies involve the estimation of $\mathrm{N}$ content (Netto et al., 2005) of tree crops like Robusta coffee using the non-destructive approach, especially under agroforestry ecosystems where incoming light varies. The employment of laser-based active nitrogen sensors such as CropSpec ${ }^{\circledR}$ (Topcon, Japan) through canopy measurement is also not widely reported in scientific literature. Unlike cameras being used as passive canopy sensors, which are affected by time of day and light intensity, active nitrogen sensors like CropSpec ${ }^{\circledR}$ employ the pulse laser diode that irradiates a plant canopy and measures reflectance intensity from the canopy without relying on ambient natural light (Holland et al., 2012). Moreover, no scientific evaluation has been reported on the performance of CropSpec ${ }^{\circledR}$ (active sensor) in estimating critical levels of nitrogen in tree crops, especially Robusta coffee.

The objectives of this study are to (1) determine how well the CropSpec $\AA$ can estimate chlorophyll and critical levels of $\mathrm{N}$ in Robusta coffee (Coffea canephora) plants at different growth stages and in different field conditions; and to (2) identify appropriate vegetation indices obtained from the sensors in estimating critical levels of nitrogen in Robusta coffee plants.

\section{MATERIALS AND METHODS}

The study was conducted at the Indonesia Coffee and Cocoa Research Institute (ICCRI), Jember, Indonesia ( $\left.8^{\circ} 15^{\prime} 24.6^{\prime \prime} \mathrm{S} 113^{\circ} 36^{\prime} 45.1^{\prime \prime} \mathrm{E}\right)$, located in East Java, Jember, Indonesia. Two different plantations with less shaded trees and properly shaded trees were used in the field-experiments. Plants aged between 2 to 10 years were randomly chosen. In total, 40 Robusta coffee plants were selected from the whole, including 20 plants from each plantation representing different field conditions. To reduce the risk of bias or error, the plants chosen were not affected by pests and diseases, and had no other symptoms of infestation (Widjaja Putra and Soni, 2017a, b).

In this study, we tried three different approaches to $\mathrm{N}$ estimation. The first approach was above-canopy measurement using CropSpec ${ }^{\circledR}$. The second approach was direct-leaf measurement using SPAD-502 chlorophyll meter. The third approach was using chemical analysis of leaf tissue in laboratory to determine the actual $\mathrm{N}$ content in each plant.

CropSpec ${ }^{\circledR}$ offers a sufficiency index (SI) from canopy reflectance of near infra-red (NIR) and red-edge (RE) regions, which can be attributed to plant properties including nitrogen, chlorophyll content, and green leaf biomass.

The CropSpec ${ }^{\circledR}$ active sensor was used to collect data on canopy reflectance across each plot. The S1 value obtained from this sensor was employed to estimate the $\mathrm{N}$ status. The $\mathrm{S} 1$ consists of NIR and RE bands with the wavelength ranges 800-810 and 730-740 nm, respectively. Spectral reflectance data could be easily recorded on-thego as a text file on the internal memory of TopCon System 150 Console Controller (TopCon, Japan).

The footprint of the CropSpec ${ }^{\circledR}$ sensor is a stripline that could be adjusted depending on the height of the platform. The strip-line footprint is advantageous in scanning trees. We measured eight different points within the footprint, spread radially, based on the branch direction. The sensor was held $\sim 1 \mathrm{~m}$ above the target, and the platform was adjusted depending on the leaf and plant conditions (Fig. 1). Measurement was conducted between $\sim 45-90^{\circ}$, depending on different plant and leaf conditions, until the sensor footprint reached the leaves in each measured branch. Black cloth was used over the area (i.e. soil covered by weeds) to reduce the measurement error. This sensor uses laser beam and thus is not affected by natural light intensity variation.

The average reflectance values from different point measurements were used to compute different vegetation indices (VIs) to represent each plant. In fact, the number of branches in each plant may vary with plant health; a healthy plant provides more branches than an unhealthy plant. Because of this, we used six different measurement points. In total, 480 data items were collected for 40 plants at different growth stages and in different field conditions. 

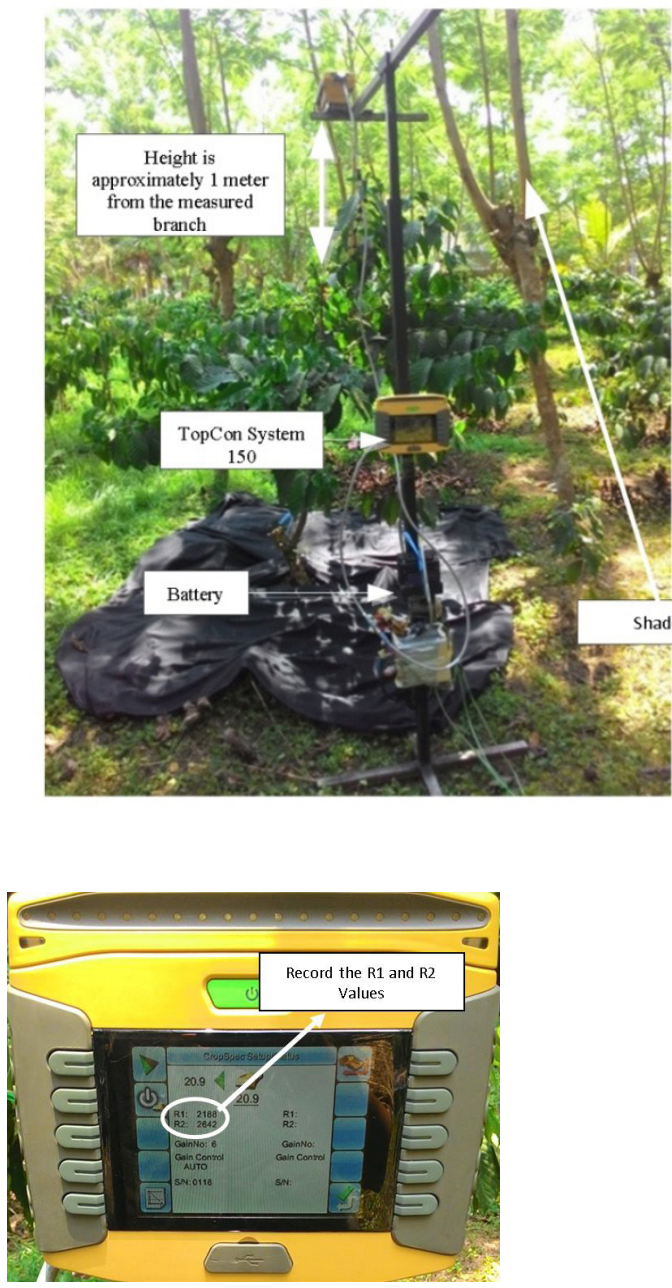

Fig. 1. Using CropSpec for assessing the biophysical properties of individual Coffea canephora plants.

Each point was repeated twice, and an average of 12 measurements was attributed to each plant. Although this sensor offers the calculated SI value as output, we employed the reflectance value of provided bands (R2 as NIR and R1 as RE) to further calculate different vegetation indices. The VIs selected for this study are listed in Table 1.

The SPAD-502 chlorophyll meter was applied for direct-leaf measurement. The SPAD-502 chlorophyll meter is widely used for measuring chlorophyll content; according to Netto et al. (2005), chlorophyll content in Robusta coffee plant obtained by the SPAD-502 chlorophyll meter is highly correlated with chlorophyll laboratory tests $\left(\mathrm{R}^{2}=\right.$ 0.94 and 0.97 for chlorophyll a and $b$, respectively). Fifteen leaves per plant (not damaged/abnormal and not affected by any pests or diseases) were selected from each plot. SPAD-502 chlorophyll meter measurements were taken eight times and averaged for individual leaves, and eventually recorded as values for individual plants (Widjaja Putra and Soni, 2017a, b).

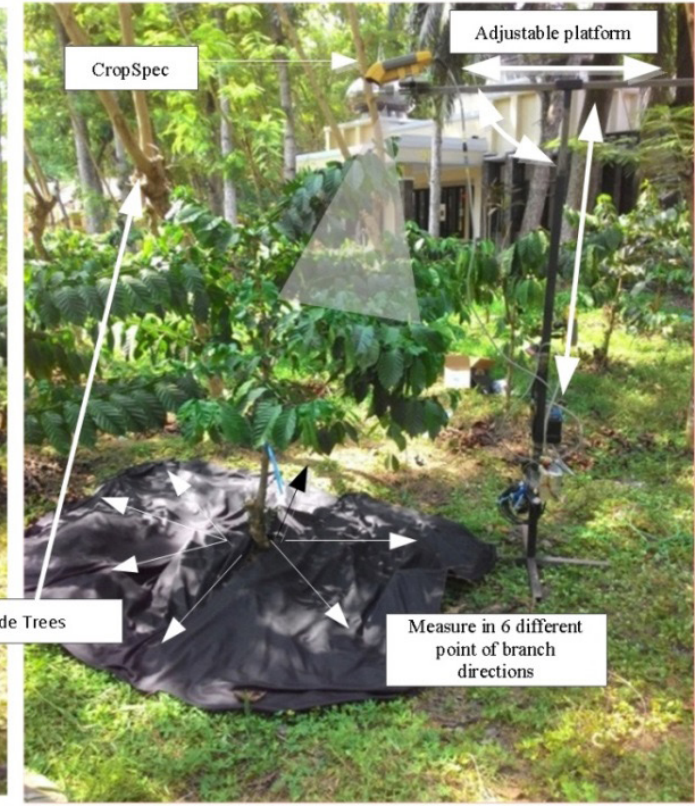

After measurement of 15 leaves from each plant using SPAD-502 chlorophyll meter, the leaves were safely taken to ICCRI laboratory for tissue chemical analysis using the Kjeldahl method (Widjaja Putra and Soni, 2017a, b). This laboratory has been standardized under the Wageningen Evaluating Program for Analytical Laboratories (WEPAL) in soils and plant tissue analysis, including the $\mathrm{N}$ estimation using the Kjeldahl method. The Kjeldahl procedure involves three stages, namely, destruction, distillation and titration. We employed this method to estimate the percentage of the nitrogen content in the leaves. Willson (1985), categorized the critical levels of $\mathrm{N}$ in Robusta coffee plants into four groups, namely deficiency, subnormal, normal, and high, with the percentage $\mathrm{N}$ levels $<1.8,1.80-2.70$, $2.71-3.30$, and $>3.30 \%$, respectively.

A total of 14 VIs were evaluated in this study (Table 1). We used these VIs to evaluate the sensitivity of CropSpec ${ }^{\circledR}$ in estimating chlorophyll and $\mathrm{N}$ content in Robusta coffee plants. In this study, we replaced the red band from existing indices with the RE band. As suggested by previous studies (Cao et al., 2013, 2016), the indices that incorporate $\mathrm{RE}$ have good potential for estimating critical levels of $\mathrm{N}$ in plants.

Performance of the developed models was evaluated by comparing the prediction results from selected models of each VI, with the $\mathrm{N}$ laboratory test values, the intent being to categorize $\mathrm{N}$ critical level status (deficient, subnormal, normal and high) for Robusta coffee plants.

Model performance was indicated by two factors (Widjaja Putra and Soni, 2017b); the first factor is the ratio of the samples proportion/distribution of critical levels of $\mathrm{N}$, as obtained from non-destructive observation and the laboratory results (\% proportion) (Eq. (1)); and the second 
Table 1. Spectral indices (selected and proposed) for CropSpec $\AA$ sensors

\begin{tabular}{|c|c|c|}
\hline Vegetation index & Formula & Reference \\
\hline Normalized R2 (NR2) & $\mathrm{NR} 2=\frac{\mathrm{R} 2}{\mathrm{R} 1+\mathrm{R} 2}$ & this study \\
\hline Normalized R1 (NR1) & $\mathrm{NR} 1=\frac{\mathrm{R} 1}{\mathrm{R} 1+\mathrm{R} 2}$ & this study \\
\hline NIR minus Red Edge (NMRE) & $\mathrm{NMRE}=\mathrm{R} 2-\mathrm{R} 1$ & this study \\
\hline Optimized vegetation index 1 (VIopt1) & VIopt1 = $100(\ln \mathrm{R} 2-\ln \mathrm{R} 1)$ & (Jasper et al., 2009) \\
\hline Modified Sufficiency Index (MSI) & $\mathrm{MSI}=\frac{(\mathrm{R} 2 / \mathrm{R} 1-1)}{\mathrm{SQRT}(\mathrm{R} 2 / \mathrm{R} 1+1)}$ & this study, modified from (Chen, 1996) \\
\hline $\begin{array}{l}\text { Red edge soil adjusted vegetation index } \\
\text { (RESAVI) }\end{array}$ & RESAVI $=\frac{1.5[(\mathrm{R} 2-\mathrm{R} 1)]}{(\mathrm{R} 2+\mathrm{R} 1+0.5)}$ & this study, modified from (Huete, 1988) \\
\hline Modified RESAVI (MRESAVI) & $\frac{2 \mathrm{R} 2+1-\mathrm{SQRT}((2 \mathrm{R} 2+1) 2-8(\mathrm{R} 2-\mathrm{R} 1))}{2}$ & modified from (Qi et al., 1994) \\
\hline $\begin{array}{l}\text { Red edge re-normalized different } \\
\text { vegetation index (RDVI-RE) }\end{array}$ & $(\mathrm{R} 2-\mathrm{R} 1) / \mathrm{SQRT}(\mathrm{R} 2+\mathrm{R} 1)$ & $\begin{array}{l}\text { this study, modified from (Roujean and } \\
\text { Breon, 1995) }\end{array}$ \\
\hline $\begin{array}{l}\text { Red edge optimal soil adjusted vegetation } \\
\text { index (REOSAVI) }\end{array}$ & $(1+0.16)(\mathrm{R} 2-\mathrm{R} 1) /(\mathrm{R} 2+\mathrm{R} 1+0.16)$ & $\begin{array}{l}\text { this study, modified from (Rondeaux et } \\
\text { al., 1996) }\end{array}$ \\
\hline EVI2RE & EVI2RE $=\frac{2.5(R 2-R 1)}{R 2+2.4 R 1+1}$ & $\begin{array}{l}\text { this study, modified from (Jiang et al., } \\
\text { 2008) }\end{array}$ \\
\hline Modified LAI & MLAI=3.618 EVI2RE-0.118 & $\begin{array}{l}\text { this study, modified from (Boegh et al., } \\
\text { 2002) }\end{array}$ \\
\hline SRRE & $\mathrm{SRRE}=\frac{\mathrm{R} 2}{\mathrm{R} 1}$ & (Gitelson et al., 1996) \\
\hline NDRE & $\mathrm{NDRE}=\frac{\mathrm{R} 2-\mathrm{R} 1}{\mathrm{R} 2+\mathrm{R} 1}$ & (Barnes et al., 2000) \\
\hline SI & $\mathrm{SI}=\frac{\mathrm{R} 2}{\mathrm{R} 1}-1$ & (Gitelson et al., 2005) \\
\hline
\end{tabular}

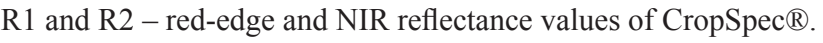

factor is the ratio of sample validity (\% validity) (Eq. (2)), as obtained from total samples diagnosed as accurate divided by total samples.

$$
\begin{gathered}
(\% \text { Proportion })=100 \% \\
\sum_{\text {Status }=\text { Low }}^{\text {High }}\left(1-\frac{\mid \text { Sample }_{\text {Lab (Status })}-\text { Sample }_{\mathrm{VI}(\text { Status })} \mid}{\text { Total Sample }}\right), \\
(\% \text { Validation })=100 \% \frac{\sum \mathrm{N}_{\text {Status }(\mathrm{VI})}}{\text { Total Sample }}
\end{gathered}
$$

where: $\Sigma \mathrm{N}_{\mathrm{Status}(\mathrm{VI})}$ obtained from the sum of $\mathrm{N}_{\mathrm{Status}(\mathrm{VI})}$ which provides number of times value ' 1 ' is obtained using the following algorithm:

if $\mathrm{N}_{\text {Status(VI) }}=\mathrm{N}_{\text {Status(LAB) }}$, then $\mathrm{N}_{\text {Status(VI) }}=1$, else $\mathrm{N}_{\text {Status(VI) }}=0$.

\section{RESULTS AND DISCUSSION}

The Pearson correlation test was used for comparing the VIs obtained from different tools. The results (Figs 2 and 3) indicated that most VIs obtained from CropSpec $\AA$ performed well in estimating critical levels of $\mathrm{N}\left(\mathrm{R}^{2}=\right.$ $0.47-0.71)$ and chlorophyll content $\left(\mathrm{R}^{2}=0.53-0.77\right)$ when applied to different samples (40 and 480 samples). While NMRE and RERDVI provided lower values than other VIs, where $\mathrm{R}^{2}$ is between 0.24 and 0.64 in estimating critical levels of $\mathrm{N}$, and between 0.26 and 0.69 in estimating chlorophyll content through SPAD readings. These are also in line with the previous studies which suggested that the combination of NIR and RE bands is adequately correlated with the chlorophyll and N content (Gitelson et al., 1996). 

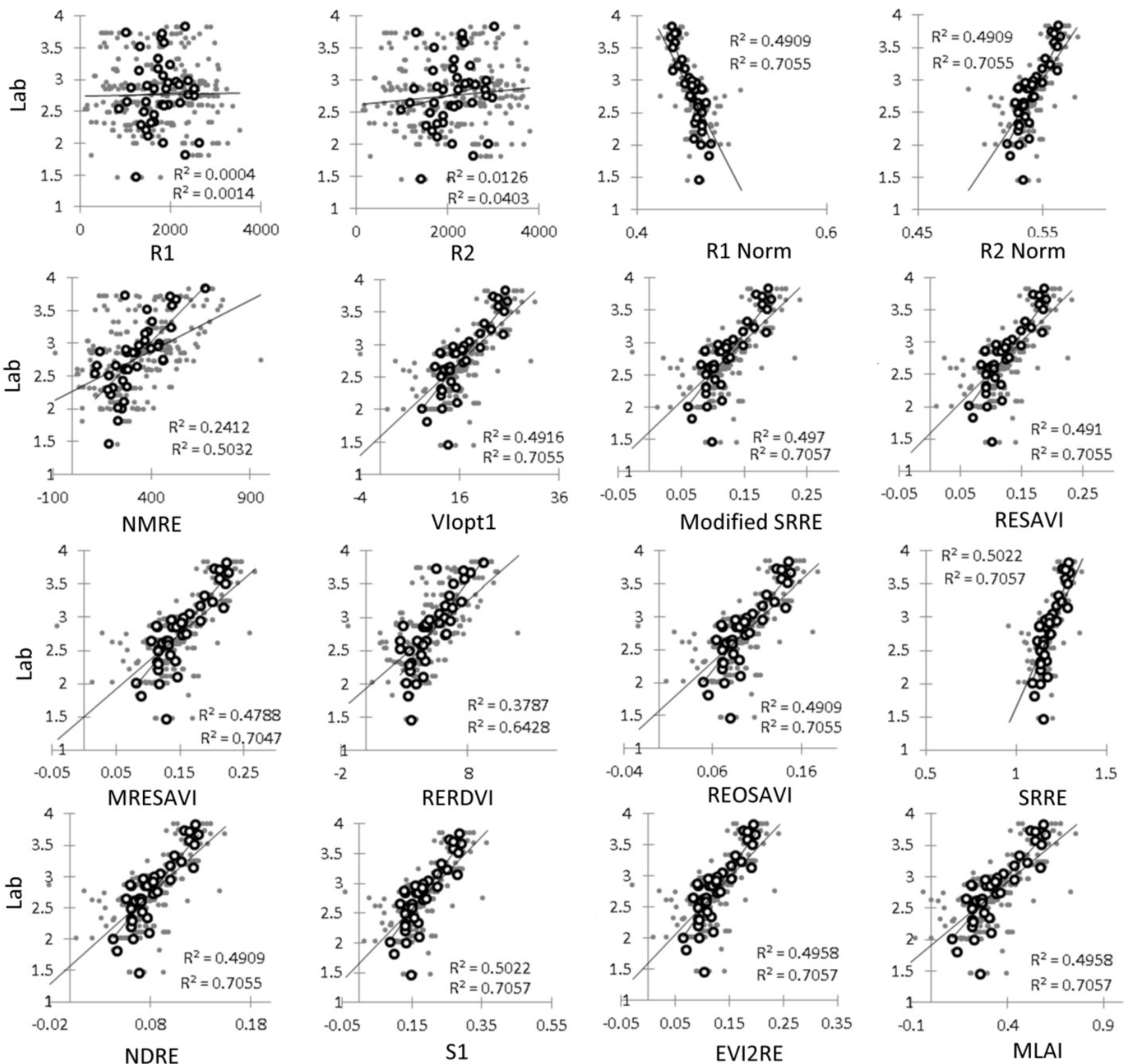

Fig. 2. Linear regression models between $\mathrm{N}$ laboratory results and VIs obtained from CropSpec ${ }^{\circledR}$ (individual point readings indicated by grey points ( $\mathrm{R}^{2}$ at upper position); plant averages indicated by black circles $\left(\mathrm{R}^{2}\right.$ at lower position)).

To improve the prediction performance, we applied multiple regression models, because the best-fitted non-linear regression did not prove significant in improving the prediction. Several studies reveal that using multiple regressions with combination of bands could enhance estimating performance for the biophysical parameters, and may potentially be a better approach than modifying the vegetation index (Cao et al., 2013; Yu et al., 2014). While modifying the VIs of CropSpec $\AA$ in the previous step provided consistent results, the generated data was still not satisfactorily enough for estimating $\mathrm{N}$ content that varied with different stages and field conditions. Although the use of individual band reflectance of R1 and R2 showed poor correlation with actual $\mathrm{N}$ values and SPAD readings (Figs 2 and 3), the combination of the two bands in multiple regression models (Table 2) performed significantly better in estimating critical levels of $\mathrm{N}$ and chlorophyll content (Fig. 4). 

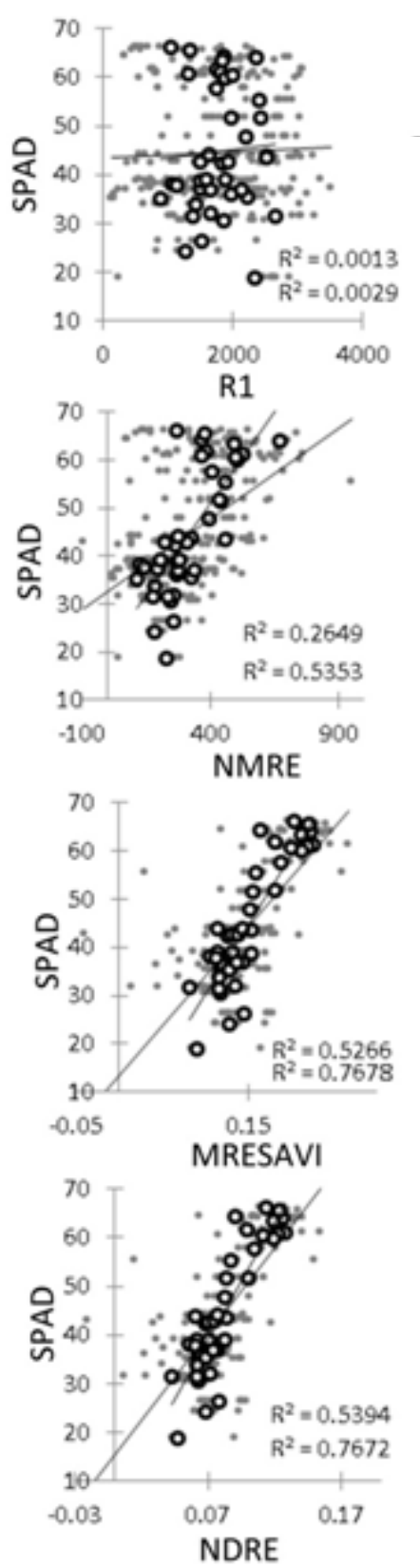
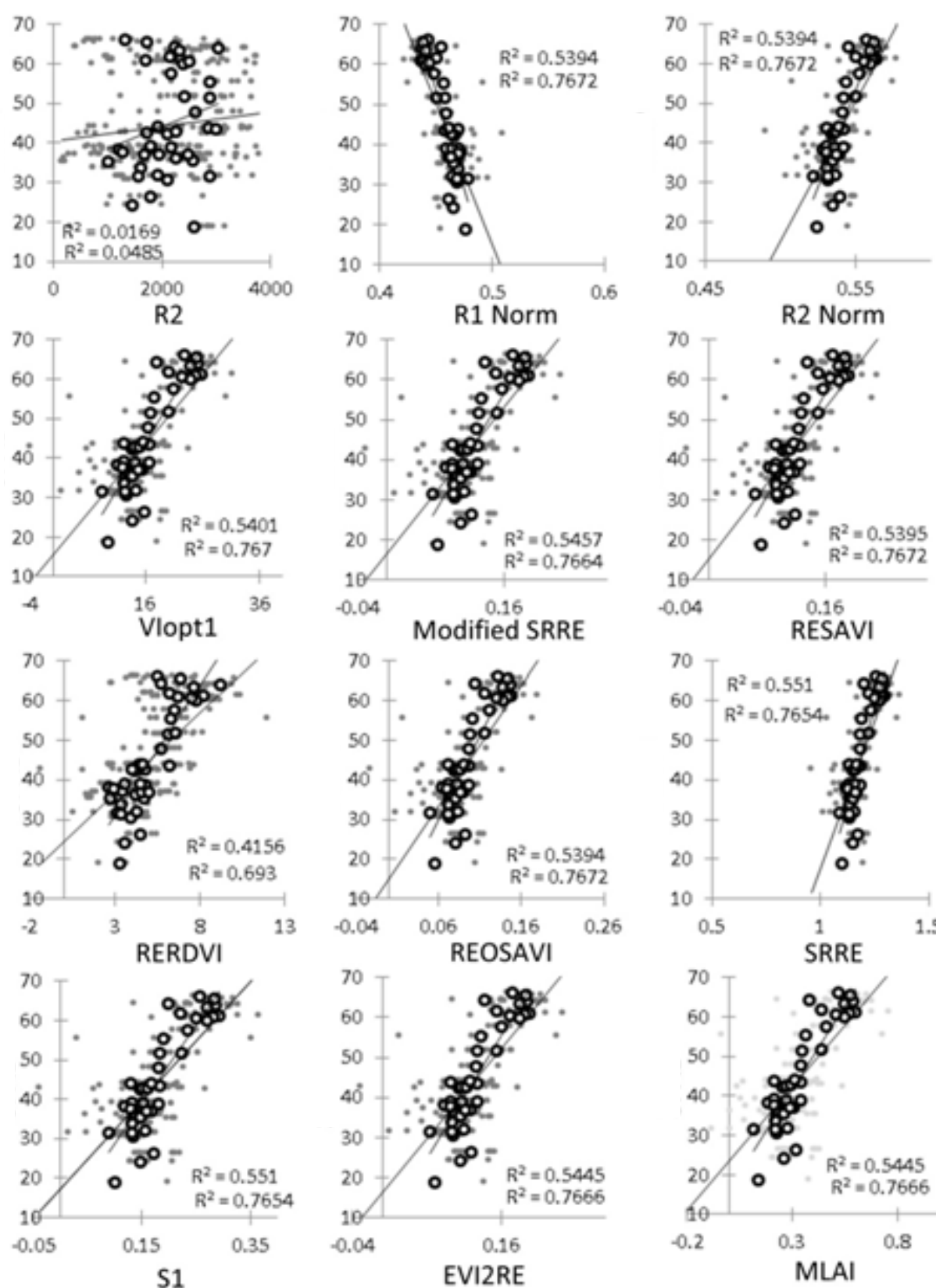

R2 Norm
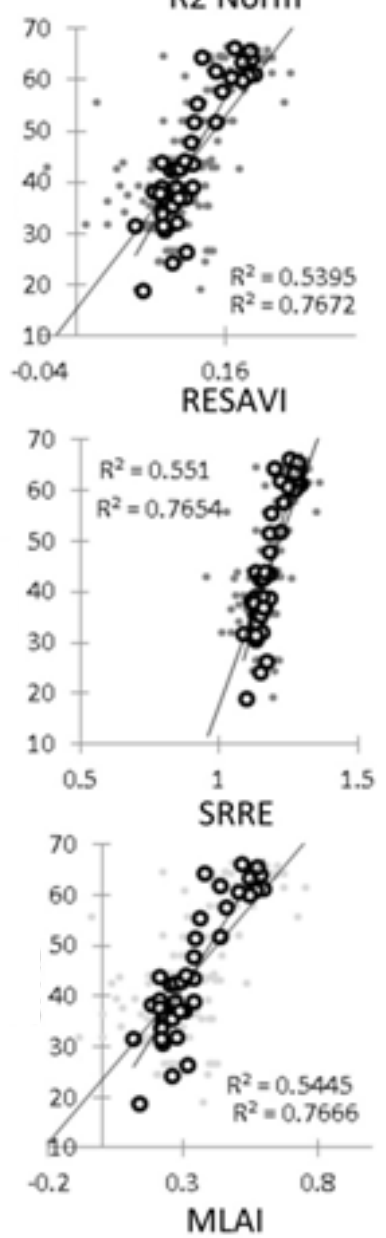

Fig. 3. Linear regression models between chlorophyll content obtained from SPAD readings and VIs obtained from CropSpec ${ }^{\circledR}$ (individual point readings indicated by grey points $\left(\mathrm{R}^{2}\right.$ at upper position); plant averages indicated by black circles $\left(\mathrm{R}^{2}\right.$ at lower position)).

A key limitation of the CropSpec ${ }^{\circledR}$ in making abovecanopy measurements of coffea canephora plants was the difficulty in getting reflectance data due to different angles (curl) of wilted leaves. In wilted condition, the background/ soil was dominant and potentially increased the error. This condition is often found in the rain-fed area, where plant leaves curl due to water shortage in the soil. Water content in the soil plays an important role in the metabolism of nutrient absorption. Although supplied with adequate fertilizer, the field that lacks water will retard $\mathrm{N}$ absorp- tion (Pessarakli, 2014). We observed that each band (R1 and R2) of CropSpec ${ }^{\circledR}$ performed well in assessing the coffee plants under different conditions (Fig. 5). Such results show the advantage of using a laser beam system such as CropSpec ${ }^{\circledR}$, which could actively compensate for the influence of light intensity variations.

Coffee is an evergreen plant, with green leaves at every stage of its growth. The highest $\mathrm{N}$ absorption is mostly during the stage of flowering and continues into the stage of filling the coffee bean (ICCRI, 1999). At this time, 
Table 2. Multiple regression models using CropSpec ${ }^{\circledR}$ in predicting $N$ status $\left(N\right.$ Lab) and $S P A D\left(Y=c+\left(a_{1} R 1+b_{1} R 2\right)+\left(a_{2} R 1^{2}+\right.\right.$ $\left.\left.b_{2} R 2^{2}\right)+\left(a_{3} R 1^{3}+b_{3} R 2^{3}\right)\right)$

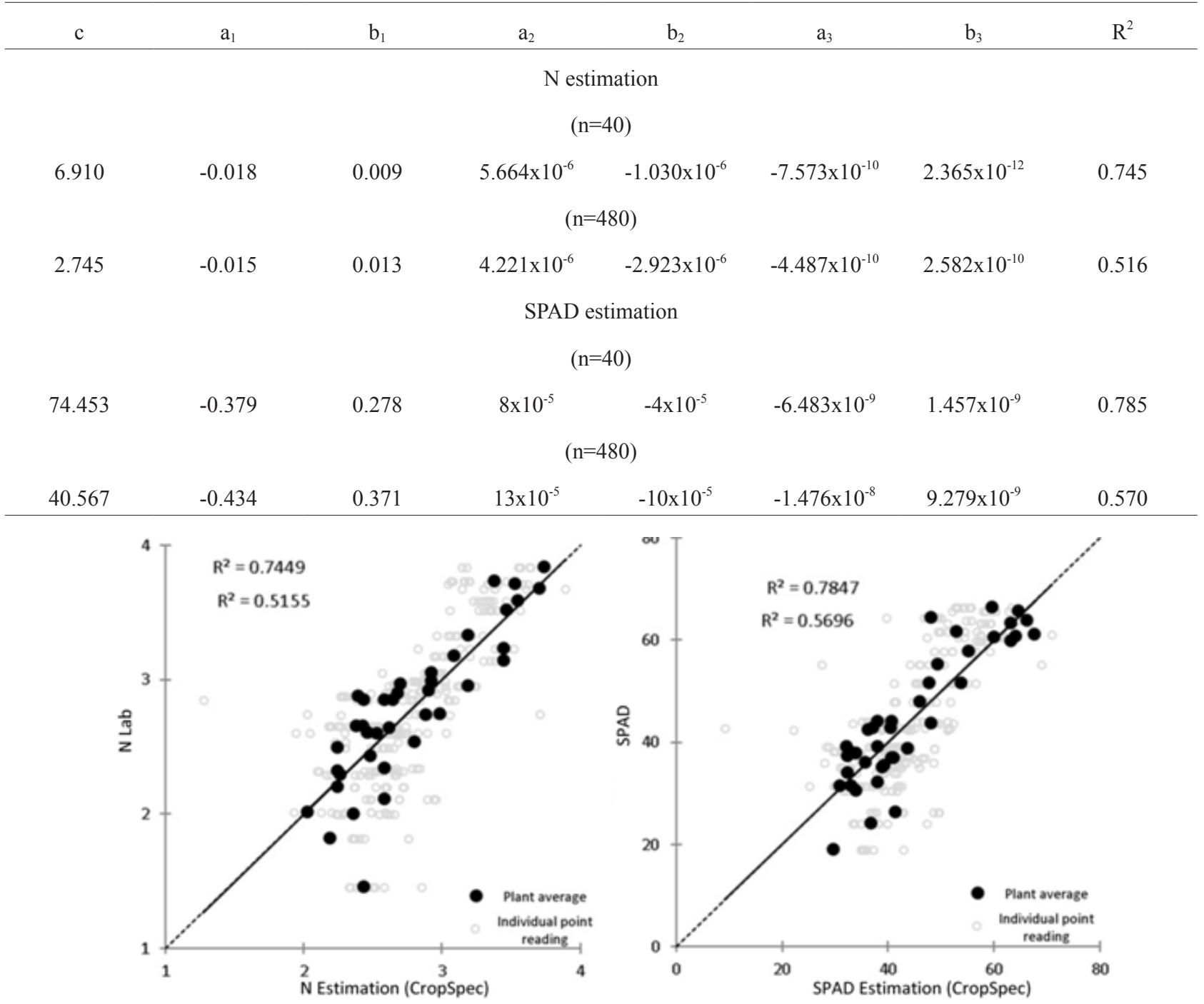

Fig. 4. Prediction using multiple regression models between CropSpec ${ }^{\circledR}$ and $N$ laboratory tests (left), and SPAD (right) (individual point readings ( $\mathrm{R}^{2}$ at upper position), plant averages $\left(\mathrm{R}^{2}\right.$ at lower position)).

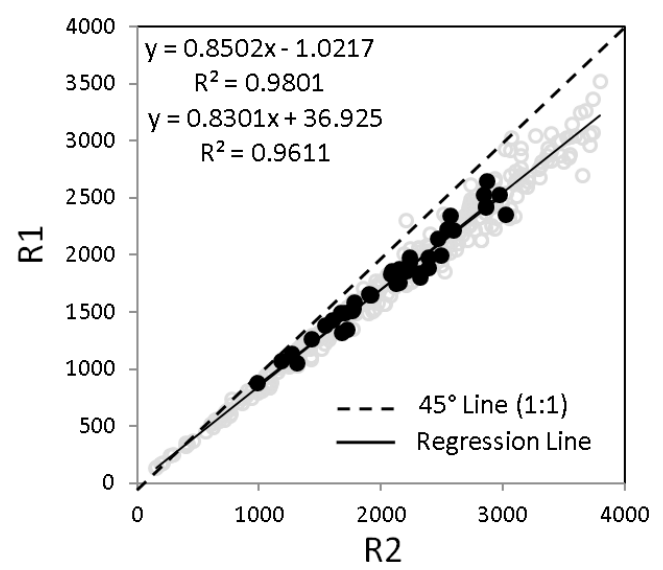

Fig. 5. Scatter plot and correlation between R1 and R2 bands of CropSpec $($ using coffee plants (individual point readings (indicated by grey points; model and $\mathrm{R}^{2}$ at lower position); plant averages (indicated by black points; model and $\mathrm{R}^{2}$ at upper position)).
$\mathrm{N}$ deficiency is easily recognized using visual identification, and is indicated by the greenness level of the plant leaves. In this step, the developed model was tested for its performance in estimating critical levels of $\mathrm{N}$ through leaf greenness justification. Our work shows that most VIs models performed consistently well for CropSpec ${ }^{\circledR}$ in estimating critical levels of $\mathrm{N}$. The provided values of validity, proportion, and RMSE were 70,75 and $0.3 \%$, respectively (Table 3).

This model performance shows that better VIs should meet three criteria in assessing $\mathrm{N}$ level status. For example, NRME provides higher value in validity and proportion, but RMSE is lower than most VIs. In other words, the prediction values obtained by this VI show more accurate categorization of each nitrogen level status based on $\mathrm{N}$ laboratory tests. 
Table 3. Model performance for vegetation indices obtained from CropSpec ${ }^{\circledR}$ with $\mathrm{N}$ laboratory tests of plant leaves (total $\mathrm{n}=40$ )

\begin{tabular}{|c|c|c|c|c|c|c|c|}
\hline \multirow{3}{*}{$\begin{array}{l}\text { Model performance } \\
\text { LAB }\end{array}$} & \multicolumn{4}{|c|}{ Proportion of nitrogen level status (n) } & \multicolumn{2}{|c|}{ Accuracy $(\%)$} & \multirow{3}{*}{ RMSE } \\
\hline & Deficient & Subnormal & Normal & High & \multirow{2}{*}{ Validity } & \multirow{2}{*}{ Proportion } & \\
\hline & 1 & 16 & 16 & 7 & & & \\
\hline R1 NORM & 0 & 22 & 10 & 8 & 70 & 75 & 0.3 \\
\hline R2 NORM & 0 & 22 & 10 & 8 & 70 & 75 & 0.3 \\
\hline NMRE & 0 & 21 & 14 & 5 & 80 & 77.5 & 0.39 \\
\hline VIopt1 & 0 & 22 & 10 & 8 & 70 & 75 & 0.3 \\
\hline Modified SRRE & 0 & 22 & 10 & 8 & 70 & 75 & 0.3 \\
\hline RESAVI & 0 & 22 & 10 & 8 & 70 & 75 & 0.3 \\
\hline MRESAVI & 0 & 22 & 10 & 8 & 70 & 75 & 0.3 \\
\hline RERDVI & 0 & 23 & 12 & 5 & 70 & 75 & 0.33 \\
\hline REOSAVI & 0 & 22 & 10 & 8 & 70 & 75 & 0.3 \\
\hline SRRE & 0 & 23 & 9 & 8 & 65 & 77.5 & 0.3 \\
\hline NDRE & 0 & 22 & 10 & 8 & 70 & 75 & 0.3 \\
\hline $\mathrm{S} 1$ & 0 & 23 & 9 & 8 & 65 & 77.5 & 0.3 \\
\hline EVI2RE & 0 & 22 & 10 & 8 & 70 & 75 & 0.3 \\
\hline MLAI & 0 & 22 & 10 & 8 & 70 & 75 & 0.3 \\
\hline Multiple regression & 0 & 23 & 9 & 8 & 65 & 72.5 & 0.3 \\
\hline
\end{tabular}

\section{CONCLUSIONS}

1. Two main approaches were compared to estimate Nitrogen and chlorophyll content on the basis of abovecanopy measurement using dual bands of CropSpec $\AA$.

2. The CropSpec $\AA$ (active sensor) performed consistently well and generated good estimations at different field conditions of Coffea canephora.

3. Careful measurement must be done due to different angle and density of leaves within a single plant.

4. We conclude that the CropSpec $\AA$ active nitrogen sensor has potential in estimating critical nitrogen status of Coffea canephora plants under field conditions.

5. More studies are needed to further evaluate the sensors for estimating nitrogen status in wilted plant conditions, pruning management and other biophysical properties, including biomass and the leaf area index of Coffea canephora.

Conflict of interest: The Authors do not declare conflict of interest.

\section{REFERENCES}

Athmaselvi K.A., Jenney P., Pavithra C., and Roy I., 2014. Physical and Biochemical properties of selected tropical fruits. Int. Agrophys., 28, 383-388.

Barnes E.M., Clarke T.R., Richards S.E., Colaizzi P.D., Haberl J., Kostrzewski M., Waller P., Choi C., Riley E., Thompson T.,
Lascano R.J., Li H., and Moran M.S., 2000. Coincident detection of crop water stress, nitrogen status and canopy density using ground based multispectral data. Proc. 5th Int. Conf. Precision Agriculture, Bloomington, MN, USA.

Boegh E., Soegaard H., Broge N., Hasager C.B., Jensen N.O., Schelde K., and Thomsen A., 2002. Airborne multispectral data for quantifying leaf area index, nitrogen concentration, and photosynthetic efficiency in agriculture. Remote Sens. Environ., 81, 179-193.

Bongiovanni R. and Lowenberg-Deboer J., 2004. Precision agriculture and sustainability. Precis. Agric., 5, 359-387.

Campbell C.A., Myers R.J.K., and Curtin D., 1995. Managing nitrogen for sustainable crop production. Fertil. Res., 42, 277-296.

Cao Q., Miao Y., Shen J., Yu W., Yuan F., Cheng S., Huang S., Wang H., Yang W., and Liu F., 2016. Improving in-season estimation of rice yield potential and responsiveness to topdressing nitrogen application with Crop Circle active crop canopy sensor. Precis. Agric., 17, 136-154.

Cao Q., Miao Y., Wang H., Huang S., Cheng S., Khosla R., and Jiang R., 2013. Non-destructive estimation of rice plant nitrogen status with Crop Circle multispectral active canopy sensor. F. Crop. Res., 154, 133-144.

Chen J.M., 1996. Evaluation of vegetation indices and a modified simple ratio for boreal applications. Can. J. Remote Sens., 22, 229-242.

Fitzgerald G., Rodriguez D., and O'Leary G., 2010. Measuring and predicting canopy nitrogen nutrition in wheat using a spectral index - The canopy chlorophyll content index (CCCI). F. Crop. Res., 116, 318-324. 
Gitelson A.A., Merzlyak M.N., and Lichtenthaler H.K., 1996. Detection of red edge position and chlorophyll content by reflectance measurements near $700 \mathrm{~nm}$. J. Plant Physiol., 148, 501-508.

Gitelson A.A., Vina A., Ciganda V., Rundquist D.C., and Arkebauer T.J., 2005. Remote estimation of canopy chlorophyll content in crops. Geophys. Res. Lett., 32, 1-4.

Holland K.H., Lamb D.W., and Schepers J.S., 2012. Radiometry of proximal active optical sensors (AOS) for agricultural sensing. IEEE J. Sel. Top. Appl. Earth Obs. Remote Sens., $5,1793-1802$.

Huete A., 1988. A soil-adjusted vegetation index (SAVI). Remote Sens. Environ., 25, 295-309.

ICCRI, 1999. Field school of integrated pest management - field guide 2: Coffee Commodity, Material Set of CRASH COURSE: Book Edition 1. Indonesian Coffee and Cocoa Research Institute, Jember, Indonesia.

Jasper J., Reusch S., and Link A., 2009. Active sensing of the N status of wheat using optimized wavelength combination: impact of seed rate, variety and growth stage. Precis. Agric., 9, 23-30.

Jiang Z., Huete A., Didan K., and Miura T., 2008. Development of a two-band enhanced vegetation index without a blue band. Remote Sens. Environ., 112, 3833-3845.

Makky M., Soni P., and Salokhe V.M., 2014. Automatic nondestructive quality inspection system for oil palm fruits. Int. Agrophys., 28, 319-329.

Netto A.T., Campostrini E., Oliveira J.G. de, and BressanSmith R.E., 2005. Photosynthetic pigments, nitrogen, chlorophyll a fluorescence and SPAD-502 readings in coffee leaves. Sci. Hortic. (Amsterdam)., 104, 199-209.

Ortiz R., Sayre K.D., Govaerts B., Gupta R., Subbarao G.V., Ban T., Hodson D., Dixon J.M., Ortiz-Monasterio J.I., and Reynolds M., 2008. Climate change: Can wheat beat the heat? Agric. Ecosyst. Environ., 126, 46-58.
Pessarakli M., 2014. Handbook of plant and crop physiology. CRC Press, Florida, USA.

Qi J., Chehbouni A., Huete A.R., Kerr Y.H., and Sorooshian S., 1994. A modified soil adjusted vegetation index. Remote Sens. Environ., 48, 119-126.

Riccardi M., Mele G., Pulvento C., Lavini A., D'Andria R., and Jacobsen S.-E., 2014. Non-destructive evaluation of chlorophyll content in quinoa and amaranth leaves by simple and multiple regression analysis of RGB image components. Photosynth. Res., 120, 263-272.

Rondeaux G., Steven M., and Baret F., 1996. Optimization of soil-adjusted vegetation indices. Remote Sens. Environ,. 55, 95-107.

Roujean J.-L. and Breon F.-M., 1995. Estimating PAR absorbed by vegetation from bidirectional reflectance measurements. Remote Sens. Environ., 51, 375-384.

Sitthaphanit S., Limpinuntana V., Toomsan B., Panchaban S., and Bell R.W., 2009. Fertiliser strategies for improved nutrient use efficiency on sandy soils in high rainfall regimes. Nutr. Cycl. Agroecosystems, 85, 123-139.

Widjaja Putra B.T. and Soni P., 2017a. Evaluating NIR-Red and NIR-Red edge external filters with digital cameras for assessing vegetation indices under different illumination. Infrared Phys. Technol., 81, 148-156.

Widjaja Putra B.T. and Soni P., 2017b. Enhanced broadband greenness in assessing Chlorophyll a and b, Carotenoid, and Nitrogen in Robusta coffee plantations using a digital camera. Precis. Agric., 19, 238-256.

Willson C., 1985. Coffee: Botany, Biochemistry and Production of Beans and Beverage (Eds M.N. Clifford, K.C. Willson). Springer US, Boston, MA, USA

Yu K., Lenz-Wiedemann V., Chen X., and Bareth G., 2014. Estimating leaf chlorophyll of barley at different growth stages using spectral indices to reduce soil background and canopy structure effects. ISPRS J. Photogramm. Remote Sens., 97, 58-77. 